\title{
Is Video-Assisted Thoracoscopic Surgical Decortication Possible for Stage III Pleural Empyema?
}

Lok Yuh Ing ${ }^{1 *}$, Mohamad Arif ${ }^{2}$

${ }^{1,2}$ Department of Cardiothoracic Surgery, Hospital Serdang, Selangor, Malaysia

DOI: $10.36347 /$ sjams.2021.v09i04.010

| Received: 06.03.2021 | Accepted: 05.04.2021 | Published: 07.04.2021

*Corresponding author: Lok Yuh Ing

Abstract

Background: Video-assisted thoracoscopic surgical decortication (VATSD) is widely applicable in fibropurulent (Stage II) pleural empyema. However, there is limited number of existing reports regarding the management of organizing (Stage III) pleural empyema via VATSD. Hence, we evaluated the effectiveness and perioperative clinical outcomes of VATSD in both Stage II and Stage III pleural empyema. Methods: A retrospective review of patients who diagnosed as Stage II and Stage III pleural empyema in Serdang Hospital from June 2018 to June 2019 who underwent VATSD and/or thoracotomy was performed. The perioperative outcomes including surgical effectiveness, duration of postoperative hospital stay, postoperative morbidity and mortality were analysed. Results: Out of total 21 patients, $10(48 \%)$ patients had Stage II pleural empyema and 11 patients $(52 \%)$ had Stage III pleural empyema. The causes of pleural empyema were pneumonia $(16,76 \%)$, infection secondary to prolonged tube thoracostomy $(2,10 \%)$, undrained hemothorax post chest trauma $(2,10 \%)$ and pulmonary tuberculosis (PTB) $(1,4 \%)$. All Stage II pleural empyema completed VATSD successfully whereas $9(43 \%)$ patients of Stage III pleural empyema completed VATSD successfully and $2(10 \%)$ patients required conversion to decortication. The surgical effectiveness and postoperative complications treated with VATSD in terms of length of hospital stay, air leak, pain, wound infection, empyema recurrence, and mortality were not statistically different between Stage II and Stage III pleural empyema. Conclusions: VATSD is an effective and safe treatment option for patient with Stage II pleural empyema and feasible in most Stage III pleural empyema with low conversion rate to open decortication.

Keywords: Video-assisted thoracoscopic surgical decortication, Stage II pleural empyema, Stage III pleural empyema. Copyright $\odot 2021$ The Author(s): This is an open-access article distributed under the terms of the Creative Commons Attribution 4.0 International License (CC BY-NC 4.0) which permits unrestricted use, distribution, and reproduction in any medium for non-commercial use provided the original author and source are credited.

\section{INTRODUCTION}

The incidence of pleural empyema is increasing worldwide [1] and it is associated with significant prolonged hospitalization and mortality. Pleural empyema is commonly caused by bacterial pneumonia. Other causes include PTB, lung abscess, and complications after thoracic surgery and chest trauma. Rarely, pleural empyema can occur after thoracentesis or tube thoracostomy[2].

Pleural empyema is categorised into three phases: exudative phase (Stage I) is characterized by thin serous pleural effusion, $\mathrm{pH}>7.2$, lactate dehydrogenase $(\mathrm{LDH})<1000 \mathrm{IU} / \mathrm{L}$, glucose $>60 \mathrm{mg} / \mathrm{dl}$, negative culture, and no loculation; fibrinopurulent phase (Stage II) is characterized by a thick purulent fluid with thin fibrin strands, $\mathrm{pH}<7.2, \mathrm{LDH}>1000 \mathrm{IU} / \mathrm{I}$, glucose $<60 \mathrm{mg} / \mathrm{dl}$, positive culture and increased loculation; organizing phase (Stage III) is characterized by a thick fibrous peel with lung encasement in addition to Stage II characteristics[3].

Stage I pleural empyema is regularly treated by antibiotic and/or tube thoracostomy[1]. However, Stage II and Stage III pleural empyema often require surgical intervention to remove visceral cortex (pleural fibrin) and loculation to achieve full lung expansion [4]. There is general agreement that Stage II pleural empyema should be treated by VATSD in view of VATSD demonstrated better clinical outcomes with shorter hospital stay, lesser pain, reduced postoperative air leak, shorter operative time and reduced time to return to work [5]. Nevertheless, the surgical approach for Stage III pleural empyema either by VATSD or open decortication remains controversial due to difficulty in port placement because of rib crowding, dense adhesions and concern about the ability to obtain complete visceral decortication to achieve full lung expansion [6]. 
Lok Yuh Ing \& Mohamad Arif; Sch J App Med Sci, Apr, 2021; 9(4): 541-545

Hence, in this study, we evaluated the effectiveness and perioperative clinical outcomes of VATSD in Stage III pleural empyema.

\section{MeTHODS \\ Study Design and Patients}

A retrospective review of patients who diagnosed as Stage II and Stage III pleural empyema in Serdang Hospital from June 2018 to June 2019 who underwent VATSD and/or thoracotomy was performed. All patients underwent laboratory investigations of complete blood count, pleural fluid analysis, and microbiological exam which include gram stain, culture and sensitivity $(\mathrm{C}+\mathrm{S})$, acid-fast bacilli (AFB) stain and culture for TB. Besides, all patients had radiological investigations of chest X-ray (CXR) and contrastenhanced computerized tomography scan (CECT) thorax to confirm presence of loculation and thickened visceral cortex preoperatively. Inclusion criteria were unsuccessful treatment with antibiotic and/or tube thoracostomy, persistent pleural loculation and thickened visceral cortex on radiological investigations. Exclusion criteria were lung abscess and lung cancer.

Video-assisted thoracoscopic surgery (VATS) was commenced in all empyema patients to diagnose empyema stage and VATSD was attempted. However, if VATSD failed, conversion to thoracotomy and decortication was performed. After decortication surgery, two chest drains were inserted and maintained on suction with -10 to $-20 \mathrm{~cm} \mathrm{H}_{2} \mathrm{O}$ at least 48 to 72 hours depending on the severity of air leak and degree of lung collapse. Chest drains were removed when drainage was $<100 \mathrm{mls} / 24$ hours and no air leak was detected. After removal of chest drains, CXR was repeated to evaluate surgical effectiveness or treatment outcomes by comparison with baseline findings. Treatment success was defined as complete evacuation of pleural loculation and restoration of complete lung expansion or slightly diminished followed by hospital discharge whereas treatment failure was defined as requirement of additional surgical intervention to treat pleural empyema. After discharge, patients will be followed up in outpatient clinic at second week and sixth week of discharge with CXR. If CXR of patient showed increased effusion compared to CXR upon discharge, CECT thorax was done to confirm the presence of recurrent empyema.

\section{Data Collection and Analysis}

Baseline characteristics were obtained from electronic medical records. These included age, gender, and duration of symptoms, side of empyema and aetiologies of empyema. The perioperative outcomes including length of postoperative hospital stay, duration of postoperative chest drainage, persistent air leak (air leak $>5$ days), pain scoring, wound infection, surgical effectiveness or treatment outcomes, recurrence of empyema within 6 weeks after surgery, and postoperative mortality within 30 days were analyzed.

Quantitative variables were described as mean and standard deviation and qualitative variables as absolute number and percentages. Mann-Whitney U test was performed to compare continuous variables whereas the chi-square test was used to compare categorical variables. The variables with $\mathrm{P}<0.05$ were considered significant. The software SPSS (Statistical Package for the Social Sciences, version 20) were used for statistical analysis.

\section{Surgical Technique}

VATSD was done under general anaesthesia. Patient was intubated with double lumen endotracheal tube and single lung ventilation. He/she was then placed in posterolateral thoracotomy position with the pleural empyema side position up. Two-port VATS was used but the locations of working port and camera port were dependent on the case and location of pathology. $10 \mathrm{~mm}$ $30^{\circ}$ angle rigid thoracoscope was inserted to stage empyema and to visualise pleural cavity. After material for microbiologic analysis was collected, fluid and loculations were removed followed by adhesiolysis from the apex to the diaphragm and the fissures. Subsequently, decortication of the parietal and visceral cortex was carried out [Figure 1]. Nevertheless, if VATSD failed, conversion to posterolateral thoracotomy and decortication was performed. Once decortication is done, the pleural cavity was rinsed with several litres of warm saline. Lastly, two large-bore chest tubes were inserted to the apex and the base to drain the fluid and air.

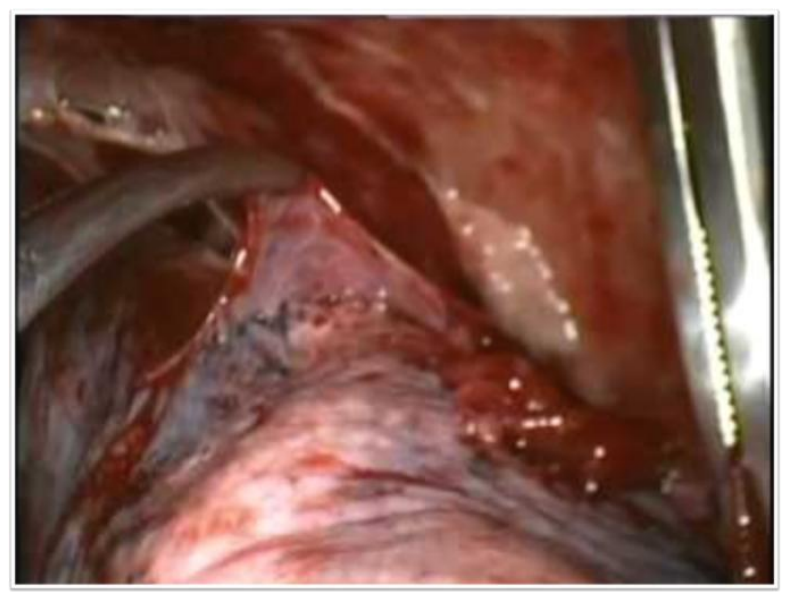

Fig-1: Decortication of visceral cortex via VATS approach

\section{RESULTS}

From June 2018 to June 2019, total of 21 patients (16 males and 5 females) underwent VATSD and/or thoracotomy, age ranging from 21 to 77 years old (mean age $40.5 \pm 16.6)$. Out of 21 patients, $10(48 \%)$ patients had Stage II pleural empyema and 11 patients 
Lok Yuh Ing \& Mohamad Arif; Sch J App Med Sci, Apr, 2021; 9(4): 541-545

(52\%) had Stage III pleural empyema. The commonest cause of pleural empyema was pneumonia $(16,76 \%)$ followed by infection secondary to prolonged tube thoracostomy $(2,10 \%)$, undrained hemothorax post chest trauma $(2,10 \%)$ and pulmonary tuberculosis (PTB) $(1,4 \%)$
Baseline characteristics of Stage II and Stage III pleural empyema were compared in Table 1. No significant differences were observed between Stage II and Stage III pleural empyema in terms of their mean age, gender, and duration of symptoms, side of empyema and aetiologies of empyema.

Table-1: Baseline Characteristics and Perioperative Characteristics of Patients

\begin{tabular}{|l|c|c|c|}
\hline Variables & Stage II empyema (n=10) & Stage III empyema (n=11) & P value \\
\hline Age, years & $41.3 \pm 15.6$ & $39.6 \pm 14.4$ & 0.68 \\
\hline Sex, n(\%) & & & 0.31 \\
\hline Male & $8(80)$ & $8(73)$ & \\
\hline Female & $2(20)$ & $3(27)$ & \\
\hline Symptoms duration, n(\%) & & & 0.06 \\
\hline$<\mathbf{3}$ weeks & $10(100)$ & $4(36)$ & \\
\hline$>\mathbf{3}$ weeks & $0(0)$ & $7(64)$ & 0.26 \\
\hline Effusion side, n(\%) & & & \\
\hline Left & $4(40)$ & $7(64)$ & \\
\hline Right & $6(60)$ & $4(36)$ & 0.43 \\
\hline Causes of empyema, n(\%) & & & 0.27 \\
\hline Pneumonia & $7(70)$ & $9(82)$ & 0.66 \\
\hline Prolonged tube thoracostomy & $2(20)$ & $0(0)$ & 0.32 \\
\hline Undrained hemothorax & $1(10)$ & $1(9)$ & \\
\hline Pulmonary tuberculosis & $0(0)$ & $1(9)$ & \\
\hline
\end{tabular}

Analyses of postoperative complications and surgical effectiveness or treatment outcomes in relation to Stage II and Stage III pleural empyema were shown in Table 2. All Stage II pleural empyema completed VATSD successfully whereas $9(82 \%)$ patients of Stage III pleural empyema completed VATSD successfully and $2(18 \%)$ patients required conversion to thoracotomy and decortication. The postoperative complications in terms of length of postoperative hospital stay, duration of postoperative chest drainage, persistent air leak, pain scoring, wound infection, recurrence of empyema, postoperative mortality, and treatment outcomes did not differ significantly between Stage II and Stage III pleural empyema.

Table-2: Postoperative Complications and Treatment Outcomes

\begin{tabular}{|l|c|c|c|}
\hline Variables & $\begin{array}{l}\text { Stage II empyema } \\
(\mathbf{n = 1 0})\end{array}$ & $\begin{array}{l}\text { Stage III empyema } \\
(\mathbf{n = 1 1})\end{array}$ & P value \\
\hline Conversion rate & $0(0)$ & $2(18)$ & 0.42 \\
\hline Length of postoperative hospital stay, days & $7 \pm 6$ & $9 \pm 5$ & 0.23 \\
\hline Duration of chest drainage, days & $5 \pm 4$ & $5 \pm 6$ & 0.42 \\
\hline Persistent air leak, n(\%) & $2(20)$ & $3(27)$ & 0.57 \\
\hline First day postoperative pain (10-point numeric scale) & $2 \pm 3$ & $2 \pm 9$ & 0.38 \\
\hline Wound infection, n(\%) & $2(20)$ & $1(9)$ & 0.42 \\
\hline Recurrence of empyema, n(\%) & $0(0)$ & $1(9)$ & 0.23 \\
\hline Perioperative mortality, n(\%) & $0(0)$ & $0(0)$ & -- \\
\hline Treatment outcomes & & & 0.31 \\
\hline Treatment success & $10(100)$ & $10(91)$ & \\
\hline Treatment failure & $0(0)$ & $1(9)$ & \\
\hline
\end{tabular}

\section{DISCUSSION}

Pleural empyema is a worldwide problem that affects all age groups and carries a significant rate of morbidity and mortality with pneumonia as the commonest cause [2]. In our study, 21 patients were diagnosed with Stage II and Stage III pleural empyema, age ranging from 21 to 77 years old and $16(76 \%)$ patients were caused by bacterial pneumonia. The development of pleural empyema is a progressive process and is classified into three phases which are exudative (Stage I) phase, fibrinopurulent (Stage II) phase, and organizing (Stage III) phase. The classification of pleural empyema depends on many determinants which include pleural fluid biochemical analysis $(\mathrm{pH}, \mathrm{LDH}$, glucose), microbiologic analysis (gram stain, $\mathrm{AFB}, \mathrm{C}+\mathrm{S}$ ), and radiographic investigations (CXR, CECT thorax). Some studies determine the empyema stage according to the duration of preoperative symptom in addition to laboratory and radiological investigations $(<3$ weeks $=$ Stage II 
Lok Yuh Ing \& Mohamad Arif; Sch J App Med Sci, Apr, 2021; 9(4): 541-545

empyema; >3 weeks = Stage III empyema) [7]. Our study determined empyema stage based on laboratory analysis, radiological investigation and direct visualisation by using VATS.

Since the advancements of VATS techniques in 1990s, there is general agreement that Stage II (fibrinopurulent phase) pleural empyema should be treated by VATSD. However, the treatment for Stage III (organizing phase) pleural empyema remains controversial. Some authors $[8,9]$ advocate that patients with Stage III pleural empyema should be treated with VATSD in view of VATSD demonstrated better clinical outcomes [5]. Roberts utilized VATS approach in all empyema cases despite of $61.6 \%$ rate of conversion to thoracotomy [10]. On the other hand, some authors consider thoracotomy and decortication as the ideal treatment for chronic empyema $[11,12]$ to release dense adhesions between parietal and visceral pleura and to obtain adequate decortication to achieve lung reexpansion. However, some studies show thoracotomy and decortication involve increased morbidity and mortality [13, 14]. Yet there are studies showing low morbidity and mortality when performing thoracotomy and decortication [15, 16]. The 2015 European Association for Cardio-Thoracic Surgery (EACTS) guidelines favoured VATSD in patients with Stage II and Stage III pleural empyema. In our study, VATSD was attempted in all Stage II and Stage III pleural empyema patients. Only $2(18 \%)$ out of 11 patients with Stage III pleural empyema required conversion to thoracotomy and decortication due to dense adhesions and inability to perform adequate decortication. Both of these patients had preoperative symptoms $>3$ weeks and the aetiologies of empyema were bacterial pneumonia and PTB respectively. Lardinois et al. demonstrates that the conversion rate to thoracotomy for pleural empyema increases from $22 \%$ to $86 \%$ between day 12 and day 16 of presentation [17]. Besides, Chung et al. shows patients with symptoms <4 weeks had better results after VATSD compared with those patients with symptoms >4 weeks [18]. Hence, these emphasize the importance of early referral to surgery to achieve clinical benefits of VATSD with shorter duration of pleural drainage and hospital stay as well as lower mortality and morbidity. Nevertheless, VATSD in tuberculous empyema can be challenging due to extensive pleural thickening and contracted intercostal spaces. Besides, most tuberculous empyema patients in our centre had preoperative symptoms $>3$ weeks due to delayed diagnosis and delayed referral. Hence, most of our patients with tuberculous empyema ended up with conversion to thoracotomy and decortication. There are limited studies about VATSD in tuberculous empyema [19, 20].

In our study, the postoperative complications and treatment outcomes did not differ significantly between Stage II and Stage III pleural empyema. However, there was a case of empyema recurrence and treatment failure contributed by patient with tuberculous empyema. It was caused by failure of full lung expansion after decortication (trapped lung) and patient developed recurrent empyema. Eventually, patient underwent redo-thoracotomy and decortication. Outcomes after operation for tuberculous pleural empyema in general have been poor because of presence of fibrocavitary parenchymal disease, bronchopleural fistula and poor nutritional status. Hence, this again emphasizes the importance of early diagnosis and early referral to surgery to halt the progression of disease. In summary, VATSD can be carried out safely as first-line management for Stage III pleural empyema.

Limitations of our study include this study was a single centre retrospective study, the sample size was relatively small.

\section{CONCLUSION}

VATSD is an effective and safe treatment option for patient with Stage II pleural empyema and feasible in most Stage III pleural empyema with low conversion rate to open decortication.

\author{
Lists of abbreviations used \\ VATSD - Video-assisted thoracoscopic surgical \\ decortication \\ LDH - Lactate dehydrogenase \\ PTB - Pulmonary tuberculosis \\ $\mathrm{C}+\mathrm{S}-$ Culture and sensitivity \\ AFB - Acid-fast bacilli \\ CXR - Chest X-ray \\ CECT - Contrast-enhanced computerized tomography \\ scan \\ VATS - Video-assisted thoracoscopic surgery
}

\section{ACKNOWLEDGEMENTS}

This work was supported by the Department of Cardiothoracic Surgery, Serdang Hospital.

\section{Declaration of conflicting interests}

No conflicts of interest in preparing this article

\section{Funding}

research.

There was no external funding source for this

\section{REFERENCES}

1. Yu H. Management of pleural effusion, empyema, and lung abscess. Semin Intervent Radiol. 2011; 28:75-86. Back to cited text no. 4

2. Broaddus VC, Light RW. Pleural effusion. In: Broaddus VC, Mason RJ, Ernst JD. eds. Murray and Nadel's Textbook of Respiratory Medicine. 6th ed. Philadelphia, PA: Elsevier Saunders; 2016: chap 79. 
Lok Yuh Ing \& Mohamad Arif; Sch J App Med Sci, Apr, 2021; 9(4): 541-545

3. Hilliard TN, Henderson AJ, Langton Hewer SC. Management of parapneumonic effusion and empyema. Arch Dis Child. 2003; 88:915-7.

4. Weissberg D, Refaely Y. Pleural empyema: 24year experience. Ann Thorac Surg. 1996; 62:10269.

5. Cardillo G, Carleo F, Carbone L. Chronic postpneumonic pleural empyema: comparative merits of thoracoscopic versus open decortication. Eur J Cardiothorac Surg. 2009; 36: 914-8.

6. Solaini L, Prusciano F, Bagioni P. Video-assisted thoracic surgery in the treatment of pleural empyema. Surg Endosc. 2007; 21: 280-284.

7. Hajjar WM, Ahmed I, Al-Nassar SA, Alsultan RK, Alwgait WA, Alkhalaf HH, Bisht SC. Videoassisted thoracoscopic decortication for the management of late stage pleural empyema, is it feasible? Ann Thorac Med. 2016; 11:71-8

8. Thoracoscopic decortication: a role for videoassisted surgery in chronic postpneumonic pleural empyema. Waller DA, Rengarajan A Ann Thorac Surg. 2001 Jun; 71(6):1813-6.

9. Cheng YJ, Wu HH, Chou SH, Kao EL. Videoassisted thoracoscopic surgery in the treatment of chronic empyema thoracics. Surg Today. 2002; 32:19-25.

10. Roberts JR. Minimally invasive surgery in the treatment of empyema: intraoperative decision making. Ann Thorac Surg. 2003; 76:225-30.

11. [Surgical treatment of chronic pleural empyema-seven years' experience]. Petrov D, Dzhambazov V, Petkova P, Boianova L, Minchev Ts, Goranov E, Plochev M Khirurgiia (Sofiia). 2004; 60(2):25-9.

12. Lardinois D, Gock M, Pezzetta E, Buchli C, Rousson V, Furrer M. Delayed referral and gramnegative organisms increase the conversion thoracotomy rate in patients undergoing videoassisted thoracoscopic surgery for empyema. Ann Thorac Surg. 2005; 79:1851-56.

13. Surgical treatment for empyema thoracis: is videoassisted thoracic surgery "better" than thoracotomy? Chan DT, Sihoe AD, Chan S, Tsang DS, Fang B, Lee TW, Cheng LC Ann Thorac Surg. 2007 Jul; 84(1):225-31.

14. Luh SP, Chou MC, Wang LS, Chen JY, Tsai TP. Video-assisted thoracoscopic surgery in the treatment of complicated parapneumonic effusions or empyemas. Chest. 2005; 127:1427-32.

15. Empyema thoracis. Therapeutic management and outcome. LeMense GP, Strange C, Sahn SA Chest. 1995 Jun; 107(6):1532-7.

16. Decortication for chronic parapneumonic empyema: results of a prospective study. Melloni G, Carretta A, Ciriaco P, Negri G, Voci C, Augello G, Zannini P World J Surg. 2004 May; 28(5):48893.

17. Lardinois D, Gock M, Pezzetta E. Delayed referral and Gram-negative organisms increase the conversion thoracotomy rate in patients undergoing video-assisted thoracoscopic surgery for empyema. Ann Thorac Surg. 2005; 79: 1851-1856.

18. Chung JH, Lee SH, Kim KT. Optimal timing of thoracoscopic drainage and decortication for empyema. Ann Thorac Surg. 2014; 97: 224-229.

19. Liu Z, Cao S, Zhu C, Wei L, Zhang H, Li Q. Application ofthoracoscopic hybrid surgery in the treatment of stage IIItuberculous empyema. Ann Thorac Cardiovasc Surg. 2015; 21:523-8

20. Chen B, Zhang J, Ye Z. Outcomes of videoassistedthoracic surgical decortication in 274 patients with tubercu-lous empyema. Ann Thorac Cardiovasc Surg. 2015; 21:223-8. 